\title{
Ramifications Associated with Child Abuse
}

\author{
Hannah Mills, Elizabeth McCarroll \\ Department of Family Sciences, Texas Woman's University, Denton, USA \\ Email: hmills1@twu.edu, EmcCarroll@twu.edu \\ Received September $5^{\text {th }}, 2012$; revised October $7^{\text {th }}, 2012$; accepted October $20^{\text {th }}, 2012$
}

\begin{abstract}
The incidence of child abuse has become quite prevalent and may be referred to as a global phenomenon (Pala, Unalacak, \& Unluoglu, 2011). In terms of a global phenomenon, it may be significant to assess negative ramifications that are in existence for children's overall social, emotional, and cognitive maturation (DeOliveira, Bailey, Moran, \& Pederson, 2004). Specifically, preschool children who are abused within their home environments are less likely to detect variations in emotional expressions as compared to preschoolers who have not been abused (Pollak, Cicchetti, Hornung, \& Reed, 2000). In regards to the domain of cognitive development, children who are reared in abusive home environments are likely to display overactive behaviors and exhibit less concentration (Schatz, Smith, Borkowski, Whitman, \& Keogh, 2008). In relation, children reared in abusive environments are less likely to perform at high levels in regards to their math and reading abilities (Crozer \& Barth, 2005). Thus, the act of child abuse may also be better well understood by assessing parenting styles and how they play a role with affecting the type of behaviors they elicit towards their children (Baumrind, 1994). For instance, specific traits or factors related to individuals' parenting abilities, such as stress, depression, domestic violence, incarceration, and psychological difficulties may be more likely to abuse their children as opposed to parents who do not obtain these traits or factors (Nair, Schular, Black, Kettinger, \& Harrington, 2003). Implications in regards to the prevalence of child abuse may be quite significant, especially considering psychological ramifications that may surface due to the act of children's exposure to abuse (Johnson et al., 2002). For instance, children may be more likely to suppress, or internalize their emotions due to the exposure to child abuse and they may be more likely to externalize, or exhibit certain behaviors in an outward fashion towards others due to the immersion within environments comprised of child abuse (Schatz, Smith, Borkowski, Whitman, \& Keogh, 2008). Furthermore, professionals who obtain the knowledge about child abuse may better serve families and children who have experienced abuse within their lives.
\end{abstract}

Keywords: Abuse; Children; Parenting; Attachment; Developmental Domains

\section{Introduction}

It is estimated that approximately 950,000 children were abused in 2006 (Boyce, 2008). Child abuse has become a global phenomenon whose perpetrators include acquaintances, friends, caregivers, or family members (Pala et al., 2011). Child abuse is quite significant and has many ramifications. Various domains of children's development, such as emotional, social, and cognitive maturation may be directly affected due to the acts of child abuse and children's overall psychological well-being may be directly affected by parents' acts of engaging in callous behaviors towards children (Crozier \& Barth, 2005; Shipman et al., 2007; Valentino, Cicchetti, Toth, \& Rogosch, 2011).

When considering child abuse, it may be significant to define the over-arching terms associated with this act. According to Mansor and Samah (2011), child abuse is defined as maltreatment targeted towards children that come in the forms of neglect or abandonment. Abuse may also include intentional acts of verbal, psychological, or physical maltreatment directed towards children (Devaney, 2008).

This paper will describe the impacts of child abuse in relation to how it may affect many dimensions of children's development. The negative implications associated with child abuse, the impacts of exposure to child abuse and the development of attachment, children's emotional development, types of play, parenting, the current context of the topic, an assessment on the research conducted on the topic, and recommendations for future research will all be presented below.

\section{Negative Implications Associated with Child Abuse}

Negative implications may be associated with child abuse that affects many domains of children's development and wellbeing (DeOliveira et al., 2004). Previous literature has indicated that child abuse may significantly alter children's self-esteem and overall perceptions (Iwaniec, Larkin, \& McSherry, 2007). Also, children reared in abusive home environments are less likely to exhibit compassion towards others (Tanaka, Wekerle, Schmuck, \& Paglia-Boak, 2011). Parents who abuse their children, or withhold affection are more likely to jeopardize their children's development of self-esteem and self-worth, which may hold negative ramifications for children's futures (Iwaniec et al., 2007). For instance, children's psychological well-being may also be jeopardized by their caregivers' abuse.

\section{Psychological Ramifications}

A study conducted by Johnson et al. (2002) investigated psychological ramifications acquired by children who have experienced child abuse within their environments. Measurements utilized included the Child Behavior Checklist and a 
Trauma Checklist for Children (Johnson et al., 2002). MANOVA tests were conducted, which included assessed whether the independent variables (being a victim of child abuse, and witnessing violence) surfaced as factors that predict the outcomes of the dependent variables (levels of aggression exhibited by caregivers, reports of depression provided by children and caregivers, and children's exhibition of anger and anxiety). Results from the study indicated that children who were reared in abusive home environments were more likely to develop depression, aggression, anger, as well as anxiety, $p$ $<.05$. In addition, children were more likely to internalize and externalize their behaviors if they were reared in abusive homes, $p<.01$ (Schatz et al., 2008). Examples of internalizing behaviors include suppressing emotions, which may lead to the development of depression. Conversely, externalizing behaviors entail the exhibition of aggression.

\section{Exposure to Child Abuse and the Development of Attachment}

Attachment plays a vital role in an individual's psychosocial development. Literature has indicated that children who were reared in abusive family environments are more likely to obtain disorganized, or insecure attachments with their caregivers as compared to children who were reared in home environments where they possess secure attachments with their caregivers (DeOliveira et al., 2004). Children who form disorganized, or insecure attachments with their caregivers are likely to lack care or concern for others and are more likely to develop anxiety and depression as compared to children who hold secure attachments with their caregivers (Becker-Weidman, 2009).

\section{Attachment Theory}

Bowlby (1988) stated that attachment may be defined as a relationship formed between caregivers and their children. Children form attachments with their caregivers based upon a sense of security, or belonging (Bowlby, 1982). Attachment relationships that children obtain with their caregivers may be labeled as secure or insecure. Secure attachment is defined as children's assurance that their caregiver will be present, or involved within their lives (Bowlby, 1982). Children who are securely attached are less likely to fear strangers and are more likely to perceive their caregivers as a secure base that will constantly be present (Bowlby, 1988).

Conversely, children who possess insecure attachments with their caregivers are likely to exhibit traits related to insecurity of their return. Children who are insecurely attached are also less likely to explore their environments as compared to securely attached children (Bowlby, 1982). Ramifications associated with insecure attachment may emerge. For instance, children are more likely to develop anxiety disorders and depression as compared to children who attain secure attachments with their caregivers (Scott, 2011).

\section{Implications Associated with Child Abuse}

Bowlby (1988) wrote that adults who are abused during the early stages of development are more likely to abuse their own children as compared to adults who were reared in homes absent of child abuse. Thus, the attachment theory may shed light into specific behaviors that caregivers exhibit, which may significantly alter the quality of attachment that children possess with their caregivers. Parents who experienced abuse as a child are less likely to form attachment relationships due to bouts of uncontrollable anger they exhibit towards their children in response to actions or behaviors (Bowlby, 1988). Mothers who are abusive are also more likely to be labeled as cold and unemotional (Bowlby, 1988). Children reared by mothers who exhibit these behaviors are likely to develop insecure attachments with their caregivers as compared to children who are reared by mothers who express empathy and care towards their children (Cicchetti \& Toth, 1995).

\section{Characteristics of Children}

Later implications may be in existence for children who have been reared in abusive environments (Bowlby, 1988). Research suggests that abuse children experience has a lasting impact on future relationships. For instance, children who have been abused and obtain insecure attachments with their caregivers are more likely to possess a fear of abandonment in relationships with others (Bowlby, 1988). Children who are reared in abusive environments are also more likely to accept physical abuse that they receive by significant others and they are more likely to accept a lack of support from others (Bowlby, 1988). Negative ramifications may be associated with children's maturation of various developmental domains, as discussed below.

\section{Children's Emotional Development}

Implications may be in existence for children's abilities to recognize emotions if they are reared in abusive environments. For instance, children reared in abusive home environments are less likely to possess the mechanisms required to properly regulate their emotions (DeOliveira et al., 2004; Schatz et al., 2008). In relation, children obtain less capability for recognizing or understanding others' emotions if reared in abusive homes (DeOliveira et al., 2004). Emotion regulation is an important factor to consider in regards to peer relationships and social development, as it impacts how children present themselves and how they respond to other people (Mills \& McCarroll, 2012).

\section{Recognition of Emotional Expressions}

A study conducted by Pollak et al. (2000) investigated whether preschoolers' exposure to violence, or abuse within their home environments would affect their abilities to recognize others' facial expressions, or emotions. Preschoolers in the experiment were asked to match facial expressions to coordinating emotional expressions and they were also asked to discriminate specific emotional expressions exhibited on facial dispositions.

Participants included 15 neglected children who ranged in ages between 3 years and 5 months to 5 years and 8 months (Pollak et al., 2000). Tasks that participants completed included an "emotion discrimination task", which asked children to discern whether children could discriminate between various types of emotions displayed as well as an "emotion differentiation task", which asked participants to determine whether certain types of emotions displayed by individuals were deemed as similar. Results indicated that abused or neglected preschoolers were less able to detect differences in emotional expressions (Pollak et al., 2000). In addition, preschoolers reared in abusive 
home environments were more likely to display a particular bias for facial expressions that displayed anger, or aggression. Specifically, Pollak et al. (2000) reported that in regards to "angry-neutral" facial expressions, maltreated children reported less differences as compared to children who were not maltreated, $F(2,28)=3.93, p<.05$, "sad neutral", $F(2,38)=4.66, p$ $<.05$, and "fearful-sad", $F(2,38)=7.35, p<.01$ (p. 683).

\section{Mothers' Reactions to Their Children}

Mothers of children who are classified as abusive are less likely to respond to infants' cries or concerns, displaying negative affect as compared to non-abusive mothers (DeOliveira et al., 2004). For instance, abusive mothers are more likely to be non-responsive to their infants or less willing to care for their infants who may exhibit distress (DeOliveira et al., 2004). Thus, mothers' inability to express sensitive attunement towards their children may be related to the fact that they did not develop this capability when they were young. In relation, mothers who were reared in abusive home environments may be less likely to express skills related to emotion regulation due to the lack of exposure to these traits when they were young (DeOliveira et al., 2004).

\section{Emotion Regulation}

In regards to emotion regulation, literature has indicated that children who were reared in abusive home environments may be less likely to obtain the abilities to regulate their emotions as compared to children who were reared in non-abusive environments (Shipman et al., 2007). The ability to regulate oneself, or regulate emotions occurs by 3 years of age (Schatz et al., 2008). Therefore, parents or caregivers may be quite influential in terms of assisting children's development of emotion regulation (Schatz et al., 2008).

Research conducted by Shipman et al. (2007) investigated the significance of abuse on children's abilities to regulate their emotions. Among the measurements used included a child maltreatment scale, labeled the CTS-PC as well as children's emotion regulation abilities, based upon results from completion of the Emotion Regulation Checklist (ERC). In addition, interaction styles exhibited by caregivers and their children as well as caregivers' reactions to their children's behaviors were measured by utilizing the Parent-Child Emotion Interaction Task (PCEIT). An additional instrument, labeled the Meta-Emotion Interview Parent-Version was used for the purposes of assessing caregivers' emotional responses to their children's behaviors (Shipman et al., 2007). Repeated measures ANOVA tests were conducted on "emotion socialization procedures", while MANOVA tests were performed on children's levels of emotion regulation. Shipman et al. (2007) reported that children who were maltreated were less likely to regulate their emotions as compared to children who were not maltreated, $F(2,76)=$ $8.65, p<.001$. Also, Shipman et al. (2007) reported that mothers in the study who were classified as abusive were also less likely to provide emotional coaching or assist children's abilities to recognize and control their emotions as compared to mothers who are not abusive, $F(1,74)=8.18, p<.01$. Also, mothers who maltreated their children were less likely to validate their children's emotions, $F(2,150)=3.53, p<.05$.

\section{Social Development}

Child abuse may hold significant implications for children's social development (Valentino et al., 2011). When considering the development of social development, a consideration of the roles of play should be considered, as it may serve as a significant role in terms of fostering this developmental domain (Valentino et al., 2011). For instance, children's participation in play may create opportunities for the establishment of social interactions with others, which may greatly foster their maturation within this developmental domain (Valentino et al., 2011).

\section{Types of Play}

Specific types of play interactions may differ between parents who abuse their children as opposed to parents who do not abuse their children (Valentino et al., 2011). A longitudinal study conducted by Valentino et al. (2011) investigated variations in play interactions displayed by parents who abuse their children and parents who do not. To investigate this phenomena, researchers utilized a classification system labeled the "Maltreatment Classification System", that denoted the type of abuse that children received from their parents, which was either categorized as physical or emotional (Valentino et al., 2011: p. 1284). In addition, children's interactions with their mothers were observed by utilizing the "Language Free Play" assessment (Valentino et al., 2011: p. 1284). During the observation, children's play behaviors were also analyzed and recorded in relation to how they interacted in their environments, with their mothers by utilizing a measurement labeled the "ABA Paradigm" (Valentino et al., 2011: p. 1284). In addition, children's cognitive abilities were measured using the BSID-II (Valentino et al., 2011).

ANCOVA analyses were conducted that assessed mother's behaviors, children's gender and cognitive abilities, which indicated significant results, $F(2,70),=6.81, p<.01$. Specifically, Valentino et al. (2011) concluded that toddlers who were reared in abusive home environments were less likely to engage in child-directed play, $(M=4.08, S D=2.2)$ as compared to children from non-abusive families, $(M=6.18, S D=2.1)$.

\section{Cognitive Development}

Children reared in environments consumed with child abuse, such as physical abuse or emotional neglect are more likely to obtain deficits in terms of their cognitive development abilities (Wilkerson, Johnson, \& Johnson, 2008). In terms of achievement, children reared in abusive environments are less likely to conceive the concept of time and may possess difficulties understanding mathematical concepts (Wilkerson et al., 2008). Furthermore, children reared in abusive home environments are more likely to display overactive behaviors and may be less able to concentrate as compared to children from home environments in which abuse was absent (Schatz et al., 2008).

In relation, a study conducted by Crozier and Barth (2005) investigated the impacts of child abuse on children's cognitive development by conducting interviews on children and their caregivers. An interview labeled the Child Interview and Assessment was designed to assess children's functioning in terms of cognitive abilities, while interviews labeled the "Current Caregiver Interview", which are directed towards caregivers were designed to collect information about the caregiver and characteristics of their children in terms of behavioral characteristics (Crozier \& Barth, 2005: p. 200). Among measurements used included the "Kaufman Brief Intelligence Test", the 
"Woodcock-McGrew-Werder Mini-Battery of Achievement", and the "Child Behavior Checklist" (Crozier \& Barth, 2005: p. 199).

Results reported from Cozier and Barth (2005) indicated that children reared in abusive environments were less likely to display traits of optimal cognitive performance abilities on national standardized tests, such as reading $\left[\mathrm{x}^{2}(\mathrm{~N}=2498)=\right.$ $17.72, p<.01]$ and math $\left[\mathrm{x}^{2}=37.66, p<.001\right]$ as compared to children who were not reared in abusive home environments.

After considering the impact of child abuse on various developmental domains, it may also be imperative to discuss the roles of parenting in relation to child abuse. For, specific types of parenting styles may be directly related to the prevalence of child abuse (Baumrind, 1994).

\section{Parenting}

The types of parenting styles elicited by individuals may greatly influence whether children are abused by their parents (Baumrind, 1994). Caregivers who exhibit parenting styles conducive of authoritarian, or demanding behaviors are more likely to abuse their children as compared to parents who display permissive or authoritative parenting styles (Baumrind, 1994).

Seminal work conducted by Baumrind (1994) may be further substantiated by Rodriguez (2010) who investigated specific types of parenting styles that were evident among those who engaged in child abuse. Among the instruments used included the Child Abuse Potential Inventory as well as the Parent-Child Conflict Tactics Scale, which measured the degree of child maltreatment that occurred within home environments. In addition, the Parenting Scale classified parenting styles that were considered to be dysfunctional (Rodriguez, 2010). The study was comprised of three parts. The first included a total of 327 participants who possessed children below the ages of 12 years, who completed an online survey that assessed their parenting styles, or abilities. The second portion of the study involved 115 parents as well as their children, who were between the ages of 7 to 12 years (Rodriguez, 2010). Parents were asked to completed the Parenting Style measure, the Child Abuse Potential Inventory, as well as the Parent-Child Conflict Tactics Scale during a scheduled session, within their homes (Rodriguez, 2010). The third set of participants included 74 mothers who were diagnosed with obtaining behavioral issues. These participants also were mothers of children between the ages of 5 to 12 years. Participants completed the Parenting Scale measurement as well as the Parent-Child Conflict Tactics Scale and the Child Abuse Potential Inventory (Rodriguez, 2010).

Results indicated that children were more likely to be abused if their caregivers displayed authoritarian or dysfunctional parenting styles. Thus, parents' "overreactivity" styles $\left(T_{2}=6.62\right.$, $p<.001)$ were greater than for parents" "laxness" scores (Rodriguez, 2010: p. 736). Furthermore, Rodriguez (2010) concluded that children were more likely to be abused by their caregivers if they lacked traits related to sensitive attunement to their children's needs.

\section{Traits of Parents}

Specific traits are in existence for parents who abuse, or maltreat their children. Traits that parents exhibit include the in- ability to control bouts of anger, or aggression through verbal and physical means (Iwaniec et al., 2007). Caregivers who have been abused are also less likely to interact with their infants as compared to caregivers who were not reared in abusive home environments (Bowlby, 1988). Thus, caregivers may be less responsive to their infants' needs, which may hold negative implications for children's development of attachment.

A study conducted by Nair et al. (2003) investigated the factors and traits of abusive mothers. Among the variables that were measured included children's cognitive, motor, and language development (Nair et al., 2003). The researchers also labeled risk factors that mothers may possess if they exhibit abuse towards their infants. Some of the factors included: parental stress, depression, domestic violence, assuming the role as a single parent, maladaptive life events, incarceration, and psychological difficulties (Nair et al., 2003). In addition, risk factors included the prevalence of substance abuse that mothers of infants used. The study implemented by Nair et al. (2003) transpired in the form of an intervention. Thus, mothers with infants between the ages of 0 to 6 years received home visits each week, while mothers of infants between the ages of 6 to 24 years received home visits every other week. Among the instruments used included the Child Abuse Potential Inventory and the Parenting Stress Index (Nair et al., 2003). In addition, infants' development was assessed using the "Bayley Scales of Infant Development" measure and the "Receptive-Expressive Emergent Language Scale" (Nair et al., 2003: p. 1005).

Results indicated that mothers were more likely to abuse their children if they possessed five of the risk factors listed above. Specifically, Nair et al. (2003) reported that the child abuse potential for the total group, which included the control and intervention groups at 6 months of assessment in regards to the five risks was $(M=264.4, S D=99.0)$, while the child abuse potential for the total group, which included the control and intervention groups after 18 months of assessment in regards to the five risks was $(M=235.8, S D=100.8)$. Nair et al. (2003) also indicated that mothers who obtain the potential to abuse their children may benefit from individuals who serve the roles as early childhood intervention specialists. Knowledge gained from such specialists may greatly reduce the potential that mothers may abuse their children (Nair et al., 2003).

\section{The Significance of Communication}

A study conducted by Ramirez, Pinzon-Rondon, and Botero (2011) assessed the significance of caregivers' communication with their children in regards to the prevalence of child abuse. Specifically, the researchers analyzed the type, or quality of communication and affection shared between caregivers and their children in regards to the frequency of acts in which children were abused by their caregivers (Ramirez et al., 2011). Participants included a total of 1089 households, with a total of 2992 children (Ramirez et al., 2011). The levels, or quality of communication expressed by caregivers was measured using the "Pacific and Atlantic Coast Family Characteristics Survey" (Ramirez et al., 2011: p. 1024). The researchers specifically assessed various types of communication patterns exhibited by participants, which included positive interactions, comprised of affection and communication as well as negative communication styles exhibited between parents and their children that measured the prevalence of abuse within children's environ- 
ments (Ramirez et al., 2011).

Hierarchical logistical models were conducted on the data to assess whether caregivers' types, or levels of communication may affect the prevalence of child abuse (Ramirez et al, 2011). Results indicated that children who obtain open communication with their caregivers were less likely to be abused as compared to children who do not possess open lines of communication with their caregivers $(\mathrm{OR}=0.02)$.

\section{Current Context of the Topic}

The current context of the topic of child abuse in regards to how it may affect various developmental domains is quite significant. Thus, research has indicated that children who have been reared in abusive home environments are more likely to experience psychological difficulties, such as depression and anxiety as compared to children who were not reared in abusive home environments (Johnson et al., 2002). Previous research conducted on this topic may shed light into the current context of the topic by providing individuals, or professionals with knowledge of the ramifications associated with child abuse (Deblinger, Mannarino, Cohen, Runyon, \& Steer, 2011). Thus, professionals who possess knowledge related to ramifications associated with child abuse may be more likely to understand manners in which to assist those who are victims of abuse.

Furthermore, the current context of child abuse may be related to seminal works, postulated by Bowlby (1988). The principles of the attachment theory may shed light into the current context of the topic by signifying the importance of the type, or quality of attachment children possess with their caregivers. Thus, children who were abused are more likely to attain an insecure attachment with their caregivers (Bowlby, 1988). Furthermore, abusive caregivers are likely to display traits related to uncontrollable bouts of aggression, absent of sincere affection (Bowlby, 1988).

\section{Critical Assessment of the Research Conducted on the Study}

Previous research has emphasized the impacts of child abuse regarding psychological ramifications that may occur as well as how it may affect children's overall development (Crozier \& Barth, 2005; Johnson et al., 2002; Pollak et al., 2000; Valentino et al., 2011). Researchers have investigated the topic of child development in a thorough fashion, by examining how this event may affect the over-arching ramifications associated with child abuse. However, researchers have not explicitly assessed how culture or ethnicity may serve as a factor towards predicting or explaining ramifications associated with child abuse (Pollak et al., 2000). Thus, culture and ethnicity may serve as foundations that significantly affect individuals' perceptions regarding abuse, which in turn may impact the way in which individuals cope with child abuse (Ramirez et al., 2011).

Previous researchers have utilized mothers and their children as participants, without considering fathers' roles in regards to child abuse (Schatz et al., 2008; Valentino et al., 2011). Thus, considering the significance of child abuse in terms of both caregivers' roles may serve the role as an impetus for assisting professionals or others working with families where child abuse is present.

\section{Recommendations for Future Research}

Recommendations for future research are abound. For in- stance, future research should incorporate fathers as participants as a manner in which to assess father-child dyads instead of solely relying on mother-child dyads to investigate implications associated with child abuse (Schatz et al., 2008; Valentino et al., 2011). Thus, the significance and implications associated with child abuse may be understood at a greater level if knowledge regarding fathers' roles in relation to child abuse is investigated (Schatz et al., 2008). Future research should also consider the roles of child abuse in regards to how it may affect the probability that children are victims of bullying by their peers (Seeds, Harkness, \& Quilty, 2010).

The recommendations listed above may provide professionals with a greater understanding of how to assist children who have been victims of child abuse. Obtaining knowledge about the role of fathers may greatly assist professionals working with families (Grief, Finney, Greene-Joyner, Minor, \& Stitt, 2007). Furthermore, assessing whether an association is evident between child abuse and bully-victimization may assist families as well as professionals within school systems.

Professionals may also benefit from future research that is targeted towards parent education. Specifically, research that highlights characteristics of parents who exhibit features related to the outward display of abuse towards their children may be quite beneficial for further understanding the significance of abuse itself. In addition, research that focuses on assessing demographic features of parents may be beneficial for further understanding the characteristics of those who exhibit aggression directed towards their children (Baciu, Voicu, Antal, Mezei, \& Roth, 2012).

\section{Conclusion}

Child abuse may obtain many negative impacts on children's development, as described above. As professionals, it is important to obtain the knowledge about the ramifications associated with child abuse so we can better understand specific characteristics that children exhibit when considering various developmental domains. It is also imperative to obtain information about child abuse so that we can recognize these behaviors and better serve children and their families.

\section{REFERENCES}

Baciu, C., Voicu, C., Antal, I., Mezei, E., \& Roth, M. (2012). Abusive parents from rural and urban areas. Social Work Review, 2, 81-89.

Baumrind, D. (1994). The social context of child maltreatment. Family Relations, 43, 360-368. doi:10.2307/585365

Becker-Weidman, A. (2009). Effects of early maltreatment on development: A descriptive study using the vineland adaptive behavior scales-II. Child Welfare: Journal of Policy, Practice, and Program, $88,137-161$

Bowlby, J. (1982). Attachment (2nd ed.). New York: Basic Books.

Bowlby, J. (1988). A secure base: Parent-child attachment and healthy human development. New York: Basic Books.

Boyce, C. A. (2008). Reauthorization of the child abuse protection and treatment act. URL (last checked 13 December 2012). http://www.hhs.gov/asl/testify/2008/ 06/t20080626a.html

Christoffersen, M. N. (2009). Prevention of child abuse and neglect and improvements in child development. Child Abuse Review, 18, 24-40.

Cicchetti, D., \& Toth, S. L. (1995). A development psychopathology perspective on child abuse and neglect. Journal of American Academy of Child Adolescent Psychiatry, 34, 541-565. doi:10.1097/00004583-199505000-00008

Cozier, J. C., \& Barth, R. P. (2005). Cognitive and academic function- 


\section{H. MILLS, E. MCCARROLL}

ing in maltreated children. Children and Schools, 27, 197-206. doi: $10.1093 / \mathrm{cs} / 27.4 .195$

Deblinger, E., Mannarino, A. P., Cohen, J. A., Runyon, M. K., \& Steer, R. A. (2011).Trauma-focused cognitive behavioral therapy for children: Impact of the trauma narrative and treatment length. Depression and Anxiety, 28, 67-75. doi:10.1002/da.20744

DeOliveira, C. A., Bailey, H. N., Moran, G., \& Pederson, D. R. (2004). Emotion socialization as a framework for understanding the devel opment of disorganized attachment. Social Development, 13, 437467. doi:10.1111/j.1467-9507.2004.00276.x

Devaney, J. (2008). Chronic child abuse and domestic violence: Children and families with long-term and complex needs. Child and Family Social Work, 13, 443-453. doi:10.1111/j.1365-2206.2008.00559.x

Grief, G. L., Finney, C., Greene-Joyner, R., Minor, S., \& Stitt, S. (2007). Fathers who are court-mandated to attend parent education groups at a child abuse prevention agency: Implications for family therapy. Family Therapy: The Journal of the California Graduate School of Family Psychology, 34, 13-26.

http://twulibraries.worldcat.org/title/family-therapy-the-journal-of-th e-california-graduate-school-of-family-psychology/oclc/4787600-21

Iwaniec, D., Larkin, E., \& McSherry, D. (2007). Emotionally harmful parenting. Child Care in Practice, 13, 203-220. doi:10.1080/13575270701353531

Johnson, R. M., Kotch, J. B., Catellier, D. J., Winsor, J. R., Dufort, V., Hunter, W., Amaya-Jackson, L. (2002). Adverse behavioral and emotional outcomes from child abuse and witnessed violence. Child Maltreatment, 7, 179-186. doi:10.1177/107755950200-7003001

Mansor, M., \& Samah, A. A. (2009). A descriptive analysis on the personality of child physical abuse victims. International Journal of Business and Social Science, 2, 229-241.

http://www.ijbssnet.com/update/index.php/side-archive.html

Mills, H., \& McCarroll, E. (2011). Emotion regulation in early childhood. Texas Child Care Quarterly, 36, 5-8.

Nair, P., Schuler, M. E., Black, M. M., Kettinger, L., \& Harrington, D. (2003). Cumulative environmental risk in substance abusing women: Early intervention, parenting stress, child abuse potential and child development. Child Abuse and Neglect, 27, 993-995. doi:10.1016/S0145-2134(03)00169-8

Pala, B., Unalacak, M., \& Unluoglu, I. (2011). Child maltreatment: Abuse and neglect. Dicle Medical Journal, 38, 121-127. $\mathrm{http}: / / \mathrm{www}$.journals.elsevier.com/child-abuse-and-neglect/
Pollak, S. D., Cicchetti, D., Hornung, K., \& Reed, A. (2000). Recognizing emotion in faces: Developmental effects of child. Developmental Psychology, 36, 679-688. doi:10.1037//0012-1649.36.5.679

Ramirez, C., Pinzon-Rondon, A. M., \& Botero, J. C. (2011). Contextual predictive factors of child sexual abuse: The role of parent-child interaction. Child Abuse and Neglect, 35, 1022-1031. doi:10.1016/j.chiabu.2011.10.004

Rodriguez, C. M. (2010). Parent-child aggression: Association with child abuse potential and parenting styles. Violence and Victims, 25, 728-741. doi:10.1891/0886-6708.25.6.728

Schatz, J. N., Smith, L. E., Borkowski, J. G., Whitman, T. L., \& Keogh, D. A. (2008). Maltreatment risk, self-regulation, and maladjustment in at-risk children. Child Abuse and Neglect, 32, 972-982. doi:10.1016/j.chiabu.2008.09.001

Scott, J. (2011). The impact of disrupted attachment on the emotional and interpersonal development of looked after children. Educational and Child Psychology, 28, 31-43.

Seeds, P. M., Harkness, K. L., \& Quilty, L. C. (2010). Parental maltreatment, bullying, and adolescent depression: Evidence for the mediating role of perceived social support. Journal of Clinical Child and Adolescent Psychology, 39, 681-692. doi:10.1080/15374416.2010.501289

Shipman, K. L., Schneider, R., Fitzgerald, M. M., Sims, C., Swisher, L., \& Edwards, A. (2007). Maternal emotion socialization in maltreating and non-maltreating families: Implications for children's emotion regulation. Social Development, 16, 268-285. doi:0.1111/.14679507.2007.00384.X

Tanaka, M., Wekerle, C., Schmuck, M. L., \& Paglia-Boak, A. (2011). The linkages among childhood maltreatment, adolescent mental health, and self-compassion in child welfare adolescents. Child Abuse and Neglect, 35, 887-898. doi:10.1016/j.chiabu.2011.07.003

Valentino, K., Cicchetti, D., Toth, S. L., \& Rogosch, F. A. (2011). Other-child play and maltreatment: A longitudinal analysis of emerging social behavior from infancy to toddlerhood. Developmental Psychology, 47, 1280-1294. doi:10.1037/a0024459

Wilkerson, D., Johnson, G., \& Johnson, R. (2008). Children of neglect with attachment and time perception deficits: Strategies and interventions. Education, 129, 343-352.

http://eric.ed.gov/ERICWebPortal/search/detailmini.jsp?_nfpb=true \&_\&ERICExtSearch_SearchValue_0=EJ871571\&ERICEx $x$ SSearch_ Type_ $0=$ no\&accno $=\bar{E} J 871571$ 